\title{
Distribution of dry matter in the plant
}

\author{
R. BROUWER
}

Institute for Biological and Chemical Research on Field Crops and Herbage, Wageningen, Netherlands

\section{Summary}

The distribution of dry matter over the various parts of the plant has been described many times as ratios, for instance as shoot/root-ratio or leaf/stem-ratio. A gradually changing ratio during the course of development indicates a growth rate of one organ favoured over the growth rate of the other. In doing so many details are overlooked. VAN DE SANDE BAKHUYZEN (1937) has introduced the method of plotting the weights of the different organs against the total weight or against the weight of an other organ. Then it appears that long periods of constant distribution occur. These periods, called phases, are of utmost importance for investigations into the physiological background of the distribution pattern.

As to changes in the distribution pattern, various causes are shortly mentioned each of which will be described more extensively in the following papers of this series.

Whereas in recent physiological literature much attention is drawn to hormonal control of growth correlations, few instances are known in which this is clearly demonstrated. This is not surprising at all as the growth substances form only one group of essentials needed for plant growth. It seems that in agricultural practice nutrition and temperature play a more important role. It cannot be expected that changing the distribution pattern can greatly enhance yield.

\section{Introduction}

After a series of lectures which dealt with the production of dry matter, at present the distribution of dry matter in the plant is treated. It stands to reason that agriculture in many cases will profit by a dry-matter accumulation which is as large as possible in the product to be harvested, for next to quality, quantity is the most important aspect. The parts which cannot be harvested in a certain sense are ballast but often a necessity, as they serve to provide the product to be harvested with essentials for its development. There is no gaining of grain without straw or sugar beets without foliage. The question that may be asked is, whether it is possible to increase the useful output by influencing the percentage of dry matter in the products to be harvested. That something can be done in this respect is proved by the influence of a late top-dressing of nitrogen (VAN DOBBEN, 1959) and of tilling the sub-soil (JONKER, 1958). Roughly this output depends, however, on the laws applying to the distribution of dry matter in the plant.

Everyone taking the plant as an object of study sooner or later is confronted with the fact that the growth rates of the various organs and - within the organs the growth rates of the different parts are so well-attuned to one another. This leads to the shape which is characteristic for each species. Morphologists as well as physiologists have described these correlations. A large part of these correlations is genetically fixed, and this applies especially to the interspecific differences. Within the genetically fixed limits, however, exterior conditions may have a modifying effect. An example may be found in BENSINK's work (1957) on the leaf shape of lettuce, 
which is dependent on light intensity as well as on nitrogen supply. The physiological phenomenon that forms the basis of these correlations is a growth correlation of the various organs. This article is mainly restricted to a description of these correlations and some suppositions as to their plant-physiological background. With regard to the title of this article, this seems a subtle change in meaning, for, growth and dry-matter increase are not absolutely synonymous. This is only the case in so far as the dry-matter percentage is constant. Roughly, this is indeed the case. Possible deviations will receive attention, while at the same time these very deviations are interestting owing to the possibilities they offer to the physiological interpretation.

\section{Dscription of the correlations between the organs}

In literature the correlations between the various organs are mainly represented by ratio's. Most commonly used is the shoot/root-ratio, but besides that also data are found on stem/leaf-ratio or grain/straw-ratio. Significant in themselves, these ratio's all the same do not give insight into the way in which they are affected. This is obtained if the method of VAN DE SANDE BAMHUYZEN is used. Although it is over twenty years ago that VAN DE SANDE BAKHUYZEN (1937) introduced his method, it is seldom used. In research at our Institute the value of this method has clearly been demonstrated. I shall begin by explaining the principles with an example.

If the growth of a plant as a whole is plotted against time a kind of S-shaped curve (FIG. 1) is obtained. During growth this applies to fresh as well as to dry weight.

FIG. 1. Dry weight (left) and fresh weight (right) of pea plants grown in climate rooms and plotted against time after emergence. Above, arithmetically; below, logarithmetically
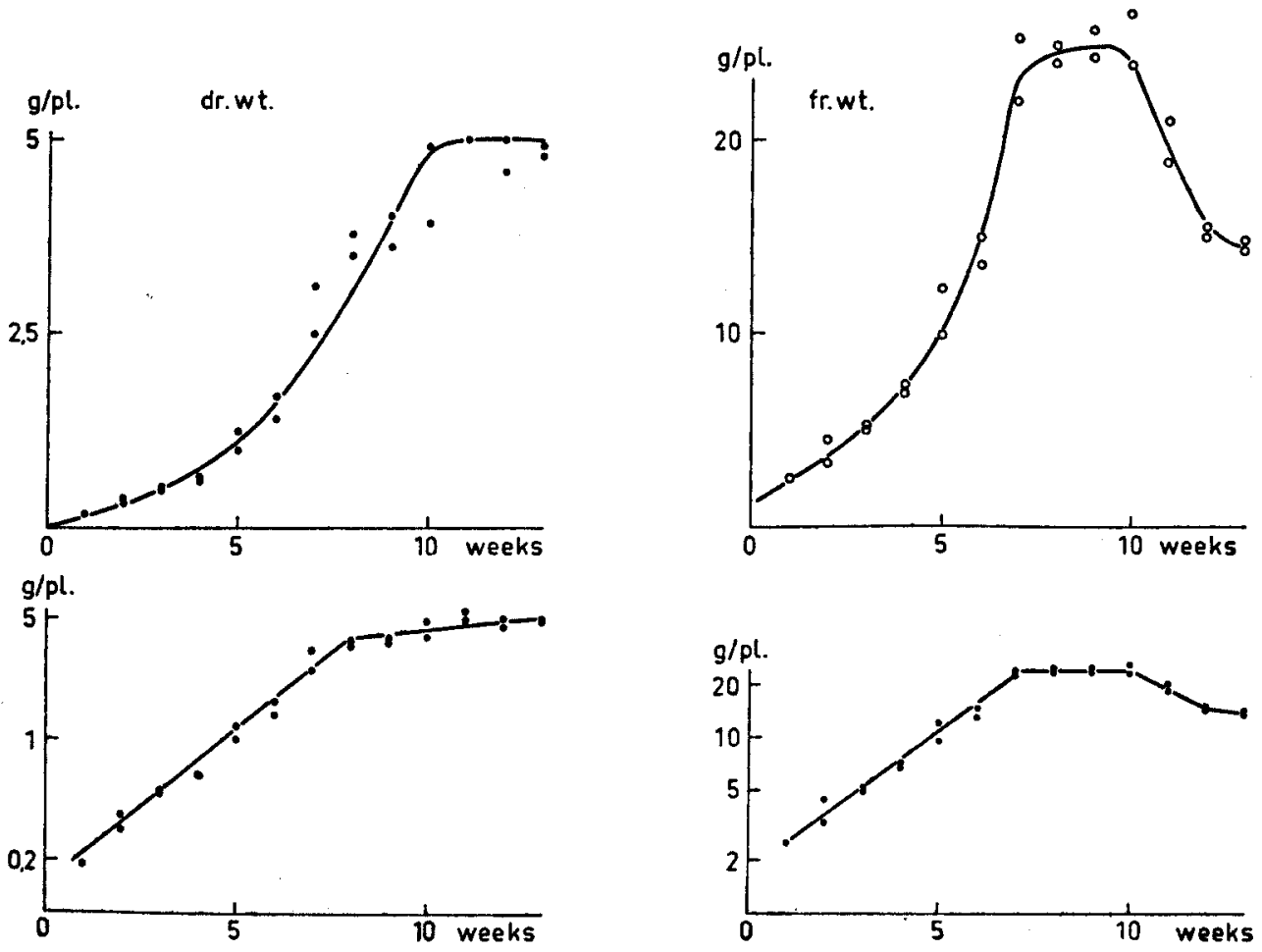
A decrease may be observed in the fresh weight at maturation. The S-shaped curve indicates that weight increase in time is more or less logarithmic. This can be checked by plotting the logarithms of the weights against time (FIG. 1) and then an approximately straight-line relationship is found, indicating indeed a logarithmic growth. At the same time it is apparent that there are corresponding points in all graphs which do not quite fit this trend. If they are found in one single experiment they may be considered deviations, but finding them repeatedly there should be a special interpretation for them (BROUWER, 1959). For the sake of simplicity this problem is not treated here. Such a growth curve, consequently, appears to be rather simple. This applies to these figures, concerning the growth of peas in environmental chambers, accordingly growing under controlled conditions, as well as to observations in the field. In reality a plant is composed of various organs. When their weights are determined and the organs are distinguished separately, an impression can be gained of the fact that this simplicity is deceptive (FIG. 2). Each separate organ has its own growth curve and these lines only partly correspond in time. Now, the growth

FIG. 2. Fresh and dry weight of the various organs of pea plants plotted against time after emergence

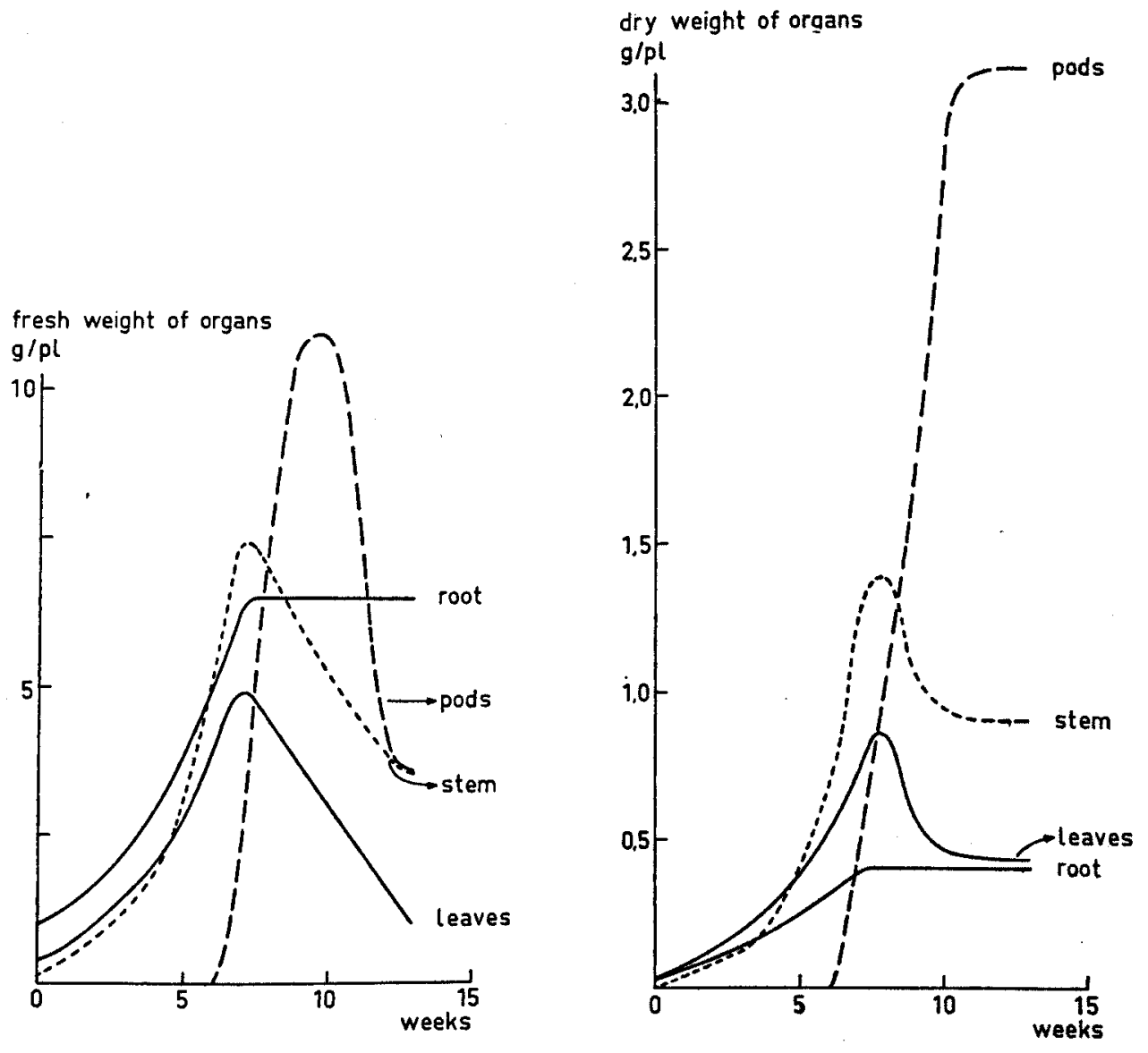


correlations are difficult to read from such a figure. The line of each organ, as reflected in this figure, is the sum of the growth curves of its separate parts. Accordingly, in this figure the leaf weight at the beginning of the experiment is the sum of the weights of 4 or 5 leaflets, which all as yet are in full growth. At the end of vegetative growth it is the sum of the weights of 20 to 21 leaflets, some of which are full-grown and others not yet. Each leaflet is again composed of various tissues and the latter of a number of cells to which the same reasoning applies. Consequently, in analysing the plant can be divided as far as to the cellular level. But in the scope of this article we will treat only the organs: root, stem, leaf and fruits.

Although the given growth curves represent the most common way of plotting, they do not give much information on the growth correlations, as has already been explained previously. If the shoot/root-ratio should be taken for this relationship, it would be a changing relation in the course of time which offers little to go by. Plotted in the way of VAN DE SANDE BAKHUYZEN, however, the data are much more allusive (FIG. 3). The distribution of dry matter being constant for long periods is the most important phenomenon found by VAN DE SANDE BaKHuYzen. These periods

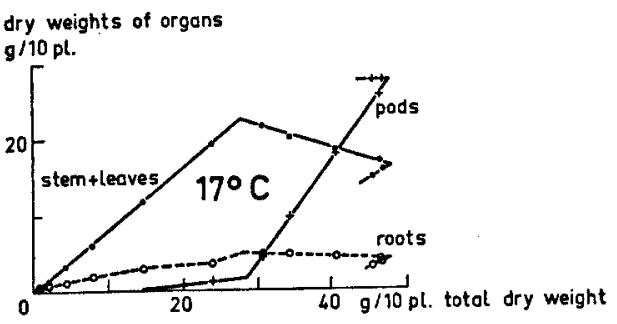

Fig. 3.

Relation between total dry weight and dry weight of various organs of pea plants at two different temperatures

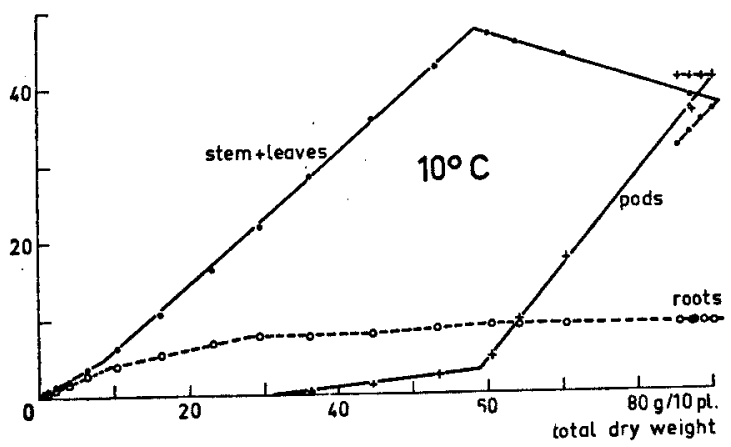

of constant distribution rather abruptly change into one another, each period representing a certain phase and these phases following each other. The constant distribution is not only found in conditioned circumstances, but also in field experiments (FIG. 4). With regard to our subject it will be interesting to know how constant growth distribution is affected per period or phase and what causes the changes from one way of distribution into another. Accordingly, there are questions into the plant-physiological bàckgrounds of these correlations. 


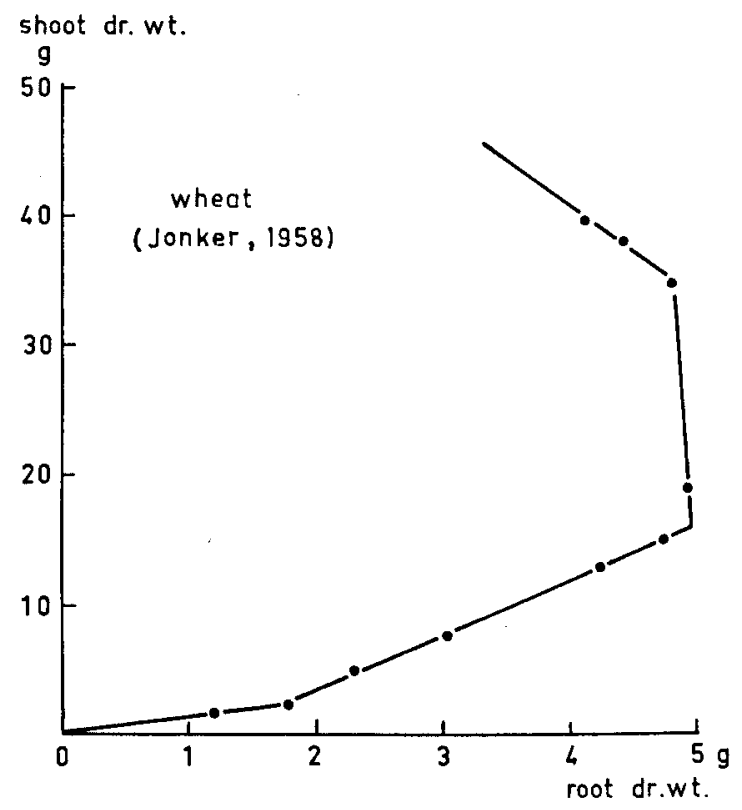

FIG. 4.

Dry weight of shoots of wheat plants plotted against dry weight of roots

\section{Posing the problem}

A growing and actively functioning organ consists of water for $90-95$ per cent. The remaining dry matter is varyingly composed and consists of organic compounds for \pm 80 to 90 per cent: carbohydrates, proteins with their building materials (the amino acids) next to the minerals. Consequently, for composing this dry matter, which may be seen as the frame in which life takes place, carbohydrates and minerals with their assimilation products are necessary. The composition and fixation of these substances in the organic whole is affected by enzymes. To affect these processes a reasonable temperature is necessary and often a good oxygen supply. Furthermore, special substances are apparently necessary for growth, which may be comprised under the name of growth substances or hormones. The building materials as well as the other factors mentioned may exercise growth-limiting actions at any time.

As for the building materials it is evident that the various organs are dependent on one another. The carbohydrates are synthesized in the green parts and the roots are completely dependent on this synthesis and transport for their carbohydrate need. Conversely, with the most common cultivation methods minerals have to be taken up by the roots and transported to the leaf in order to make leaf growth possible. As for the hormnoes, this is not much different. This has been proved by organ cultures in which a certain organ is removed from the plant in a young stage for cultivations on an artificial nutrient medium in which all the building materials mentioned are present. To obtain a growth in all aspects equal to growth on the plant itself, different, specific substances are needed from case to case.

A growing organ, therefore, is a consumer of building materials from the common store and the growth rate is a measure for the extent to which it is successful in attracting these materials. As for their supply of materials, organs growing at the same time are to be considered as competitors. A constant distribution means that each of the organs is able to appropriate a certain part of these materials. At the 
same time, it means that a certain distributive pattern is affected by regulation in one or another way. This regulation is the centre of the problem. The regulation is complicated, opinions on it are divided and a satisfactory decision is hardly possible at the present state of research.

Various aspects of this regulation will be reviewed, at the same time treating the vegetative and generative growing period separately.

\section{Vegetative growth}

It is common practice to divide the life cycle of a plant in a vegetative and generative period in which the vegetative period roughly falls between germination and flowering. At the beginning, at germination, the plant grows on the reserves in the seed. The developing root system is in direct contact with the soil and can start the water and salt uptake; the carbohydrate synthesis only starts when the sprout emerges from the soil. Many research workers has the opinion that the regulation of the relative growth rates of the various organs should be attributed to the specific substances just mentioned. The interpretation introduced by BONNER and GALSTON (1955) may be considered as representative. It may be assumed as definit that the formation and transport of certain substances necessary to the growth of an organ takes place in the way suggested. However, it is not sufficiently evident that regulation in fact is due to these substances. SödiNG (1952) consequently mentions in his book on growth substances: growth substance $\longrightarrow$ growth, but also growth $\longrightarrow$ growth substance. Which came first into existance, the egg or the chicken? The same applies to the hypothetical stem and leaf-growth substances. According to WENT those formed in the roots should regulate growth of the overground parts, while a root-growth substance formed in the shoot should have the same regulating function for root growth. To justify this conclusion it should at least be proved that the substances concerned are growth limiting and this has not been the case.

Already at a very early stage in the research on growth substances AvERY, BuRKHOLDER and CREIGHTON (1937) proved that the better the nitrogen supply, the higher the concentration of growth substances in the stem apex of sunflower seedlings is. In those cases there was a distinct correlation between growth and the concentration of growth substances, but also between growth and nitrogen supply. Application of growth substances to the non-growing plants did not produce any growth, while nitrogen application did. Accordingly, nitrogen was the growth limiting factor and not the growth substance. A distinct correlation between growth and concentration of growth substance does not always indicate a causal relationship.

Numerous are still the examples in which there is no evidence of a correlation between growth and the content of growth substances. As it is, the growth-substance pattern is so complicated that the absence of this correlation may not be considered as evidence for or against. There are so many hormone-like substances that perhaps the essential one may have been overlooked. Thimann (1954) in his argument for the regulating function of the specific growth substances even goes so far as to assume that in the absence of the correlation just mentioned the sensitivity of the organ for the growth substance may have changed. In fact, there are still many open questions, and from the collected data can not be concluded that growth substances play a part in the regulation of the relative growth of the various organs. There are, however, examples in which a certain co-ordinating effect can be attributed to the growth substance. A typical example is the apical dominancy. The 
presence of the apex of the main stem prevents the development of the axillary buds. Removing the apex immediately results in the sprouting of one or more of the axillary buds. Consequently, it looks as though the growing apex is able to attract the building materials in its direction. If the apex drops off as a main consumer, either by removal or by preventing growth in another way, the axillary branches will have their chance. As it is, it has been proved that when after removing the apex, the cut is treated with growth substance the development of the axillary branches also remains retarded. This may be considered as a commonly occurring hormonal influence. There is a good deal of literature on this subject. It has also been proved that the growth check of the axillary branches often is not complete and is dependent on the nutritive condition of the plant. Under favourable nutritive conditions of the plant axillary buds will sprout also in the presence of the apex and at an unfavourable nutritive condition axillary buds will not sprout, even after removal of the apex. Accordingly, also in this case objections can be raised to a true hormonal regulation. Our conclusion consequently must be that there are only few data in literature indicating a co-ordination of the growth of vegetative organs by growth substances. The evidence should have to come from experiments in which the distribution should have to be changed by applying growth substances occurring in nature. Although Bosemark (1954) could morphologically change the root system considerably by applying anti-growth substances, the distribution of the building materials did not appear to be changed. The only example known to me is from WhITEHEAD (1961) who could change the shoot/root-ratio in favour of the shoots by gibberellin. In many other cases in which hormone-like substances were applied no clear changes in the ratio's could be observed.

In general, an impression exists that the growth substance only forms one of the essentials for growth. We have already drawn attention to the fact that the nutritive condition also is of importance in the coordination. The nutrient-physiological influence of growth correlations is a separate chapter and will be treated in detail in a following lecture. However, the principle can be explained by a few examples. It is commonly known that the carbohydrates are made in the green parts and are transported from there to other parts of the plant. It is obvious that at an impending deficit of carbohydrates the sprout will be able to profit longest being nearest to the source (CuRTiS and CLARK, 1950) and the root, which has to receive the carbohydrates from the second-hand, will have a relatively retarded growth. In view of this it is to be expected that at low light intensity the sprout will have a relative advantage. An example of this is to be found in TABLE 1. At increasing light intensity an accelerated growth of sprout as well as root is to be expected, but a relatively more stimultated root growth. This reaction is to be expected only when growth is actually limited by carbohydrate shortage. A decrease in the carbohydrate supply

TABLE 1. Effects of light intensity on dry weights of shoots and roots and on shoot/ root-ratio of white pine seedlings (MITCHeLl and RosendaHL, 1939)

\begin{tabular}{cccc}
\hline \multirow{2}{*}{$\begin{array}{c}\text { Light intensity in } \\
\text { \% of unshadowed }\end{array}$} & \multicolumn{2}{c}{ Dry weight } & Shoot/root-ratio \\
\cline { 2 - 3 } & shoots & roots & \\
30,1 & 54,3 & 18,6 & 2,92 \\
57,0 & 72,8 & 37,2 & 1,96 \\
78,4 & 91,4 & 60,0 & 1,51 \\
100,0 & 94,3 & 68,7 & 1,37 \\
\hline
\end{tabular}


also occurs when the assimilation surface is reduced. RICHARDSON (1953) showed that root growth in such cases decreased immediately. It will be interesting to know what happens to shoot growth in such cases (FIG. 5). With these bean plants a relatively accelerated leaf growth is the result of partial defoliation. This compensatory effect is a general phenomenon that occurs after mowing grass and other fodder crops (SonNEveld, 1962) and after pruning, but also after damaging the root system by soil cultivation. Removing a part of the foliage as well as a part of the root system leads by compensatory growth to recovery of the normal proportion fitting to the given situation. Consequently, it can be observed that a decrease in the photosynthesizing system depresses root growth and relatively stimulates leaf growth. Conversely, a reduction of the root system depresses leaf growth (FIG. 5). This phenomenon is a coultrepart of the previous one. It does not concern the carbohydrates this time, but a product of root activity, minerals and water. At an impending deficit the root will have first choice this time and, accordingly, sprout growth will be affected most. There are many examples known in literature all indicating a relative increase in root growth at mineral deficiencies. The trend of this reaction in time will be treated in a subsequent lecture.

The water supply in principle has a similar influence as the mineral supply. At a decreasing availability of water the root partly growing in soil layers from which the water has as yet not been absorbed, may continue growth. The shoot obtaining water from the average rooted soil receives too little, and shows a considerable growth reduction (TABLE 2). This regulation in fact devolves on the relative growth conditions of the various organs. That may relate to internal conditions, such as carbohydrate supply or mineral supply, but also to external conditions, such as temperature or oxygen supply.

At lower temperatures the root will have the advantage. The relation between root growth and temperature shows an optimum at a lower temperature than the same relation for shoot growth. The shoot/root-ratio, therefore, increases with increasing temperature (TABLE 3). We have to be careful with regard to the physiological background of this phenomenon. Temperature affects the development greatly and with

fr.wt. leoves

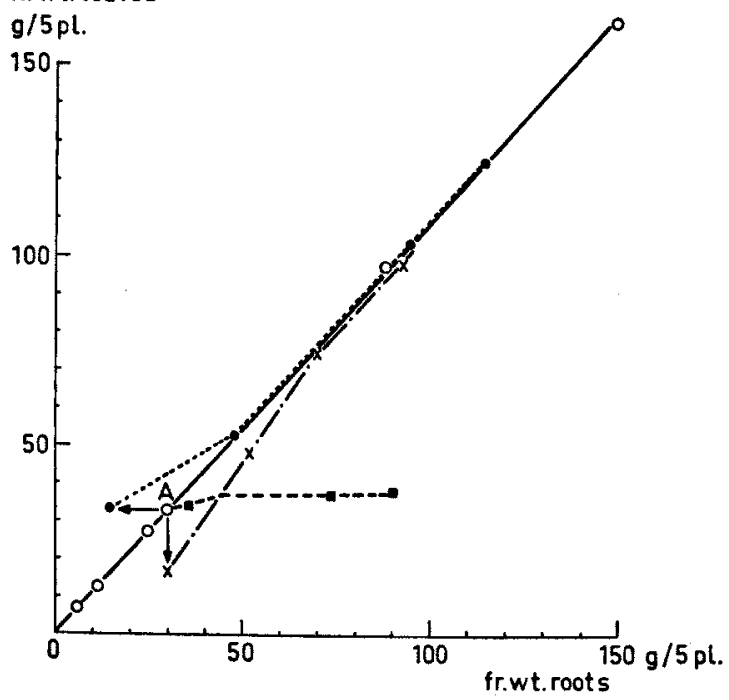

FIG. 5.

The relation between fresh weights of leaves and roots of bean plants grown on Hoagland solution in climate rooms

Open dots: normally growing plants. Black dots: plants partly derooted at point A.

Crosses: plants partly defoliated at point A.

Black squares: plants from which all leaf primordia above the two seedling leaves were removed continuously.

Note the rapid recovery to the basic line (open dots) after disturbance. 
TABLE 2. Influence of moisture level on fresh weight of shoots and roots of carrots (BARNES, 1936)

\begin{tabular}{lrrc}
\hline Moisture level & \multicolumn{2}{c}{ Weight of } & Shoot/root-ratio \\
\cline { 2 - 3 } & shoots & roots & \\
low $\ldots \ldots \ldots$ & & & \\
medium $\ldots \ldots .6$ & 22,1 & 25,6 & 0,26 \\
high $\ldots \ldots \ldots$ & 33,6 & 10,1 & 0,29 \\
\hline
\end{tabular}

TABLE 3. Shoot/root-ratios of different grass species at various temperatures (BRowN, 1939)

\begin{tabular}{|c|c|c|c|}
\hline \multirow[t]{2}{*}{ Species } & \multicolumn{3}{|c|}{ Temperature ${ }^{\circ} \mathrm{C}$} \\
\hline & $15,6^{\circ}$ & $21,1^{\circ}$ & $26,7^{\circ}$ \\
\hline Poa pratensis & 0,82 & 1,89 & 5,26 \\
\hline Poa compressa ... & 0,74 & 1,59 & 6,25 \\
\hline Dactylus glomerata & 2,61 & 2,62 & 4,16 \\
\hline Cynodon dactylon ...... & 4,79 & 6,25 & 10,0 \\
\hline
\end{tabular}

it, the shoot/root-ratio. It influences also the ratio between photosynthesis and respiration and with this the carbohydrate availability. More details are shown by vAN DOBBEN (1962).

The aeration of the root environment has a similar affect but in a reversed direction. In the first instance this is of importance for root growth which is depressed at a poor oxygen supply. It is to be expected this time that the shoot will have a relative advantage. This is often found indeed. Besides root growth being depressed by a poor aeration, the root functions are also retarded. Thus the mineral and water supply to the shoot stagnate, consequently also affecting shoot growth. It as yet depends on the extent of the retardation of root growth compared to the root functions, whether the shoot or the root will be most depressed. In tomatoes (TABLE 4) it is clear that root growth is more depressed than root activity. In beans this happens to the same extent so that a uniformly reduced growth is obtained without affecting the relation leaf/root. Many more examples are to be found in which now the first case and then again the second occurs (BrouwER and VAN VLIET, 1960).

The influence of root temperature on the shoot/root-ratio in peas shows the same trend as with aeration in tomatoes (TABLE 5). There is a distinct influence of soil temperature on root growth, which almost stands to reason. The overground parts

TABLE 4. Effects of oxygen supply on root and shoot growth of tomato plants (ERICHSON, 1946)

\begin{tabular}{llllll}
\hline & \multicolumn{5}{c}{ Oxygen supply in m.e./litre } \\
\cline { 2 - 6 } & 0,05 & 0,15 & 0,25 & 0,5 & 1,0 \\
shoot dry wt $\ldots \ldots \ldots$ & 1,31 & 2,44 & 2,68 & 2,78 & 3,11 \\
root dry wt $\ldots \ldots \ldots$ & 0,23 & 0,53 & 0,70 & 0,74 & 0,78 \\
shoot/root-ratio $\ldots \ldots$ & 5,88 & 4,47 & 3,86 & 3,77 & 4,05 \\
\hline
\end{tabular}


TABLE 5. Fresh weight of roots and shoots at different root temperatures $(\mathrm{g} / 4 \mathrm{pl}$.)

\begin{tabular}{rrrc}
\hline $\begin{array}{c}\text { Root temp. } \\
\text { in }{ }^{\circ} \mathrm{C}\end{array}$ & \multicolumn{3}{c}{$\mathrm{H}$} \\
\cline { 2 - 4 } & shoot & root & shoot/root-ratio \\
5 & 6,35 & 4,78 & \\
10 & 13,96 & 16,31 & 1,33 \\
15 & 19,47 & 21,35 & 0,85 \\
22 & 23,79 & 23,08 & 0,91 \\
31 & 13,40 & 15,25 & 1,03 \\
& & & 0,88 \\
\hline
\end{tabular}

are under the same conditions at all the different root temperatures, and the difference in growth of these parts in dependence on root temperature, consequently, has to lie in a difference in the supply of minerals and/or water by the various root systems. If activity is as much retarded as growth a non-changed shoot/root-ratio is to be expected, which is about the case with peas. If activity is more retarded than growth the highest shoot/root-ratio is to be expected at the optimal temperature as is the case with rape seed (FIG. 6). Accordingly, the root is most active and produces

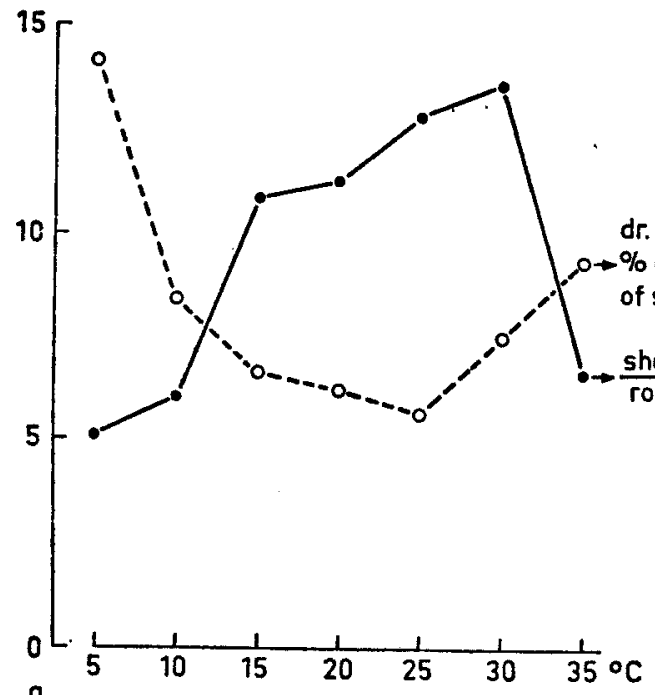

FIG. 6.

Dry weights of shoots and roots of rape seed grown at different root temperatures (below) and drymatter content of the shoots and the shoot/root-ratio (above)

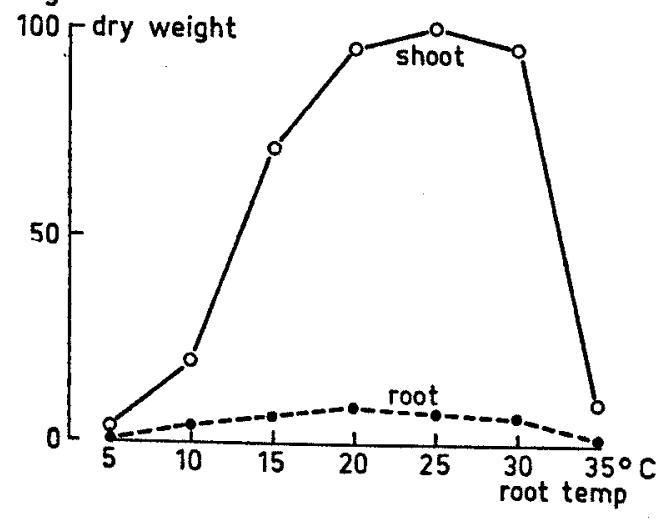

rape 
the highest shoot weight per gramme of weight where growth is optimal. In Fig. 6 also the dry-matter content of the shoot has been reflected. Hence, it appears that this content is lowest where the shoot has the highest growth rate. This is a common rule; growth inhibition not due to unsufficient photosynthesis (low light intensity) causes an increase in dry-matter content. In other words, growth as a process is much more sensitive to all kinds of deficiences than the function, in this case photosynthesis.

If the whole of this growth co-ordination is summed up in the vegetative phase it may be put that this co-ordination is nothing else but the relation of growth rates of the various organs. These growth rates are dependent on many factors. One of them is the hormone balance in the plant. Too few data are known from which appears that this indeed plays a regulating part during the vegetative phase. Another factor is temperature which undoubtedly causes the growth pattern to be different in the various seasons. In this relation the vigorous root growth in spring should be considered. The other factors of importance are of a nutrient-physiological nature. The leaf grows to an extent in which the root system can take up minerals and water. The root system grows to the extent in which the sprout produces carbohydrates. If the water and mineral supply is ample the sprout may grow vigorously. The result is that the greater part of the carbohydrates is used by the sprout itself. If this should go too far, the root cannot supply enough, which will reduce sprout growth and thus more carbohydrates will be available again for the root. Thus a kind of equilibrium is reached which is considered to be a functional balance between the organs.

\section{Generative phase}

The number of investigations into the causality of the change from the vegetative into the generative phase is extremely large. All research on the influence on flowering comes under this head. Without entering into details it may perhaps be said that this change is due to hormonal influences. In this change a new competitor is introduced into the system in the shape of the developing fruits. From the FIGS. 2 and 4 appears that with peas this new organ absorbs all the products of photosynthesis and even partly those formed previously. An exact analysis showed that the latter was especially the case in leaf and stem parts situated at the same height as the growing pods. A similar absolute dominance of fruit over vegetative growth does not always occur. There are many crops in which vegetative growth continues, although somewhat reduced during part of the generative phase. Much research indicates that by removing flowers and young fruits vegetative growth, at least the distribution of dry matter as it was previously, continued normally (FIG. 7). Consequently, it appears that nothing has changed in the vegetative part; only the presence of the competitor is of importance. It is not strange, in fact, that competition between vegetative and generative growth shows a very different trend. This is not only dependent on the plant species (perhaps not at all), but especially on all kind of external conditions.

This is already apparent immediately in the change itself. A lush growing vegetative crop changes less easily into the generative phase than a slowly thriving crop. The low growth rate, which is favourable for the change into the generative phase, as a rule is attended by an accumulation of carbohydrates, especially when $N$ is 
FIG. 7. Weight of shoots plotted against weight of roots of normally maturing tomato plants (squares) and plants after removal of flowers (dots). The latter remain vegetative and maintain a constant shoot/root-ratio

shoot fr.wt.
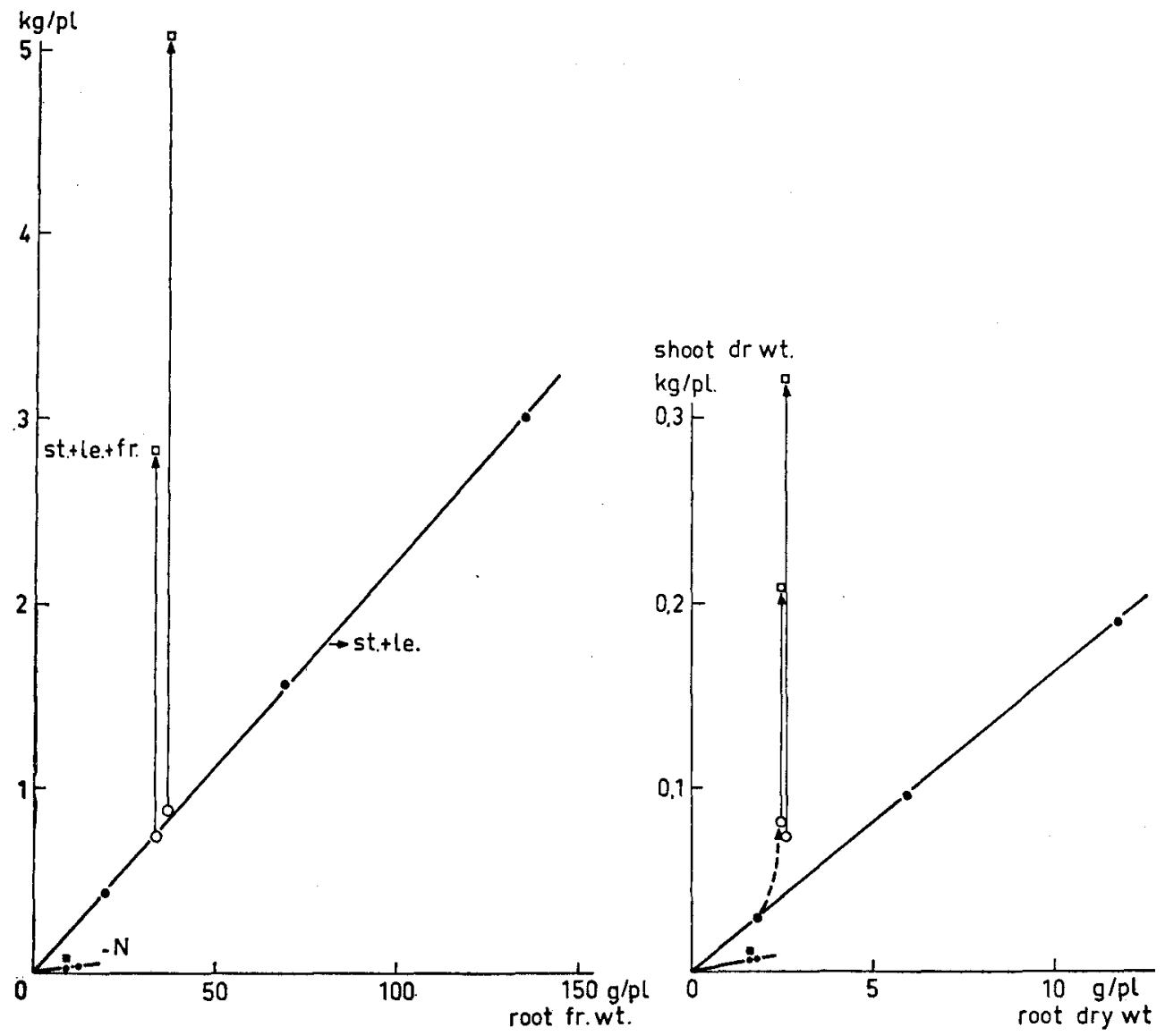

the growth-limiting factor. Hence, the great influence of the nutritive condition found by KLEBS (1910). The disputable influence of the C/N-ratio (Kraus and KRAYBILL, 1918) also is in this line. It may be assumed that due to the accelerated growth in same cases the carbohydrate reserves are so low that the change into the generative phase or the development of the fruits will be the ones to suffer. That this may indeed play a part is proved by the unsuccessful fruit setting at low light intensity, especially when it is attended by high temperatures (VERKERK, 1955). In view of this, it is interesting that WHITAKER and PRYOR (1946) were successful in improving the fruit development in melons under these conditions (low carbohydrate content) by applying growth substance to the flower. Evidently the competitive power is increased in this way, of course always in a relative way with regard to the vegetative growing points. A more usual method, therefore, is to decrease the competitive energy of the vegetative growth. Keeping the crop dry or removal of the growing points are well- 
known examples. Stimulating fruit setting by removing a part of the root system or a nitrogen deficit have the same effect. All these measures eventually lead to vegetative-growth reduction and, accordingly, to carbohydrate accumulation.

Especially the first periods, that of the change of the vegetative into the generative phase and shortly after, are very sensitive with regard to this and aid is perhaps needed. In later periods the competitive power of the fruits will be sufficient for competition with the vegetative growth. It looks as though this is associated with the production of growth substances in the young seed. In view of the fact that in most cases vegetative development at the time of the change into the generative phase has reached its maximum, the amount of leafy material present will be of paramount importance for the seed yield. This is one of the facts proved by experiments on the growth of peas at various temperatures (FIG. 8). The peas grown at the lowest temperature $\left(10^{\circ} \mathrm{C}\right)$, owing to the long period between germination and flowering and despite the lower relative growth rate develop a larger leaf system than at higher temperatures. The seed yield is about directly proportional to this vegetative development. The same phenomenon occurs in many plants and will be treated more closely by vaN DOBBEN (1962). In practice it is also well-known that a distinct correlation exists between vegetative development and seed yield. A constant grain/strawratio should have to be found in those cases. As a matter of fact, it is often found

FIG. 8. Dry and fresh weight of peas at different dates after emergence plotted against time. Arrows indicate onset of flowering

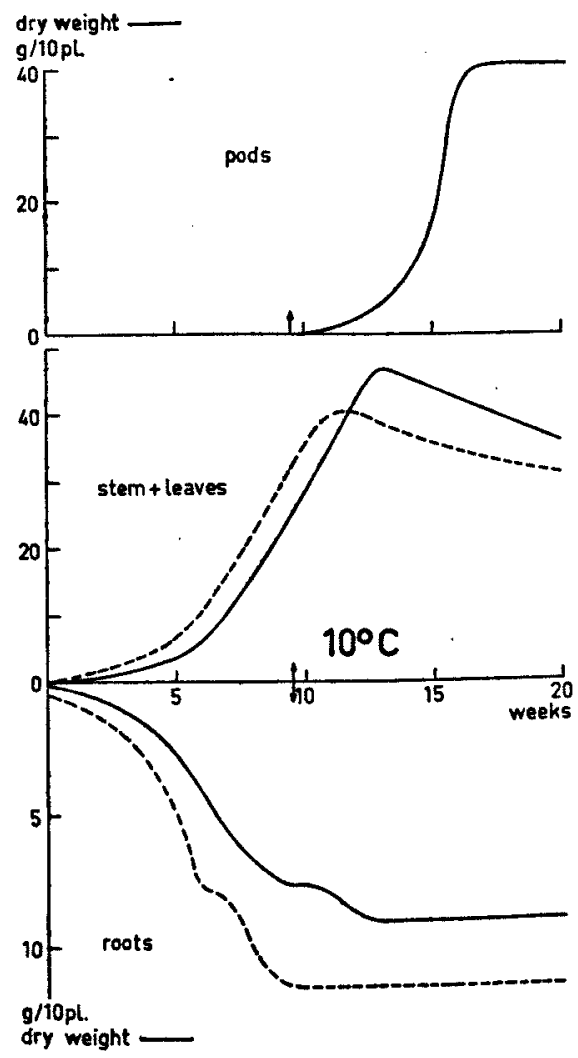

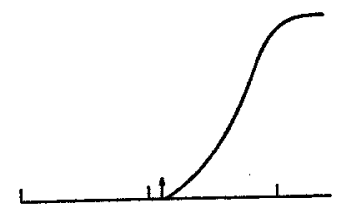
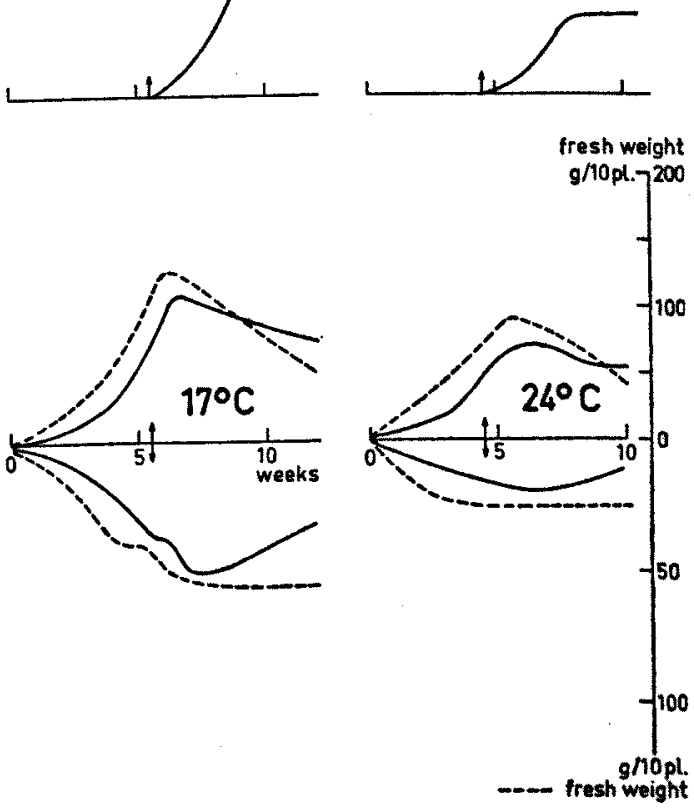


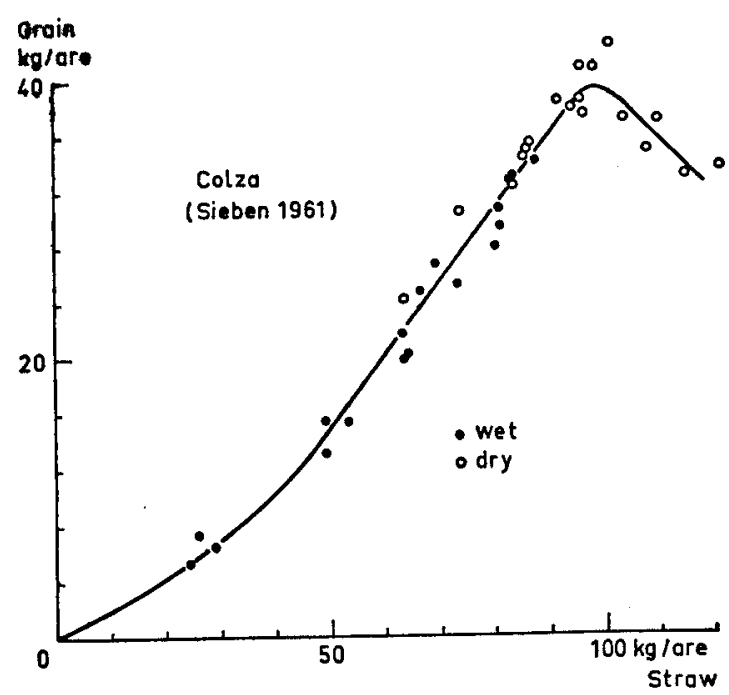

Fig. 9.

Grain weight plotted against straw weight. Colza treated with different nitrogen gifts in the Flevo Polder (derived from SIEBEN, 1961)

Note. 1 are $=0,01$ ha.

that this relation varies with the conditions. This sometimes is only partly ilucidating, as it is the same with the grain/straw-ratio as with the shoot/root-ratio. Insight is only gained if these two magnitudes are plotted against each other as has been done in FIG. 9 for rape-seed data obtained by SIEBEN (1961).

As it is evident, the straw and seed yields are increased by rising $\mathrm{N}$-fertilizations and show a rectilinear relationship over a whole traject. This does not apply to the grain/straw-ratio which gradually changes from 3,3 at the bottom of the straight part of the line to 2,3 at the top. This change in the ratio plainly is the result of the fact that the line does not continue through the origin of the axes. It has clearly been proved in these experiments that increasing the vegetative development by $\mathrm{N}$-fertilization produces a corresponding increase in the seed yield until a certain maximum is reached after which the seed yield decreases owing to lodging or insufficient ripening.

Besides the bulk of the vegetative parts, of course also the time during which they remain photosynthetically active is of importance for the seed yield. The experiments made by VAN DOBBEN (1959) on the influence of a late top-dressing of nitrogen clearly show this.

I believe a similar effect can be observed in experiments on the influence of deep soil cultivation made by JoNKer (1958) in the North-East Polder (see FIG. 10). When plotted as grain yield against straw yield these data show in a similar way as the rape-seed data do, that with $\mathrm{N}$-fertilization the straw yield increases and the seed yield proportionally as well. This is proved by the straight basis line (solid) connecting all those plots which are ploughed in the usual way. With each nitrogen fertilization deeper cultivated plots are present next to those ploughed in the usual way. It is obvious that these plots give a higher grain yield with the same straw weight. This will also be the result of the fact that the leaf surface due to the deeper soil cultivation (perhaps a better $\mathrm{N}$-supply) remains active for a longer period. This effect is canceled at the higher fertilizations. 


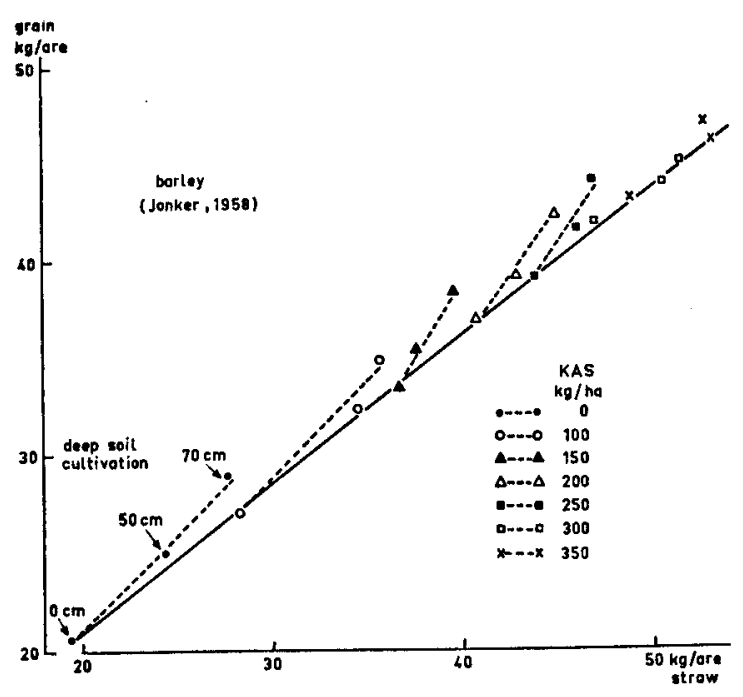

Fig. 10.

Grain weight of barley plotted against straw weight. Solid line through points with normal ploughing. In combination with the nitrogen applications two deep soil cultivations have been practised

Note. 1 are $=0,01$ ha.

\section{Conclusions}

The growth correlations found in plants between the various organs in fact are correlations between the growth rates. Consequently, as such they are governed by growth conditions internal as well as external. Changes in growing conditions often cause changes in the ratio as not all organs react on the change in the same sense. This is partly related to the interdependence of the organs. Accordingly, root growth does not react directly on shading the sprout, but indirectly on the decreased carbohydrate synthesis. This complicated relation often makes it difficult to indicate the real causes, especially where it concerns internal factors. For agricultural and horticultural practice, however, factors are of importance such as fertilization and water supply, the results of which, also theoretically founded, may easily be foretold. As for the possibilities of increasing the amount of product to be harvested we are not too optimistic if we try to find this in a change in distribution. For, these changes in favour of the relative amount of the product to be harvested generally are associated to a reduction in the other organs, and thus at the same time of the total amount of the product to be harvested.

Profit can only be expected by improving the root environment and possibly by selection for longer vegetative periods.

\section{REFERENCES}

AVEry, G. S., P. R.

1937 Am. J. Bot. 24, 553.

BURKHOLDER and

H. Creighton

Barnes, W. C.

BENSINK, J.

BONNER, J., and

A. W. Galston

BOSEMARK, N. 0.

1936 Corn. Univ. Agr. Expt. Sta. Mem. No. 186.

1957 Proc. Kon. Ned. Ak. Wet. C 61, 89.

1955 Principles of plant physiology. Freman and Company, San Fransisco.

1954 Phys. Plant. 7, 497. 
BROUWER, R.

\section{-}

Brown, E. M.

Crocker, W.

CURTIS, O. F., and

D. G. Clark

DOBBEN, W. VAN

ERICKSON, L. C.

JONKER, J. J.

KLEBS, G.

Kraus, E. J., and

H. R. KRAYBILL.

MEYER, B. S., and

D. B. ANDERSON

Mrtchell, H. L., and

R. O. ROSENDAHL

LoOMIs, W. E.

RICHARDSON, S. D.

SANDE BaKhUYZEN, H. L. VAN DE

SIEBEN, W. $H$.

SinNotT, E. W.

SöDING, $\mathrm{H}$.

Sonneveld, A.

ThimanN, K. V.

VERKERK, $\mathrm{K}$.

WENT, F. W.

WHITAKER, T. W., and D. E. PRYOR

WHITEHEAD, W. L.
1959 Jaarb. I.B.S. 1959, 17.

1962 Neth. J. agr. Sci. 10, 5 Special Issue : 399-408.

1960 Jaarb. I.B.S. 1960, 23.

1939 Univ. Mo. Agr. Expl. Sta. Res. Bull. No. 299.

1919 Bot, Gaz. 67, 445.

1950 An introduction to plant physiology. Mc. Graw Hill Book Cy, New York.

1959 Jaarb. I.B.S. 1959, 93.

1962 Neth. J. agr. Sci. 10, 5 Special Issue : 377-389.

1946 Am. J. Bot. 33, 551.

1958 Van Zee tot Land 25, 164.

1910 Proc. Roy. Soc. London. 82 B, 547.

1918 Vre. Agr. Exp. Sta. Bull. No. 149.

1952 Plant physiology. D. van Nostrand Comp., New York.

1939 Black Rock Forest Papers. 1, 88.

1953 Growth and differentiation in plants. Iowa State College Press.

1953 Proc. Kon. Ned. Ak. Wet. C 56, 346.

1937 Landbk. Tijdschr. 49, 885.

1961 Personal communication.

1960 Plant morphogenesis. Mc. Graw Hill Book Cy, New York.

1952 Die Wuchsstofflehre. Georg Thieme Verlag, Stuttgart.

1962 Neth. J. agr. Sci. 10, 5 Special Issue : 427-444.

1954 Huitième Congrès Int. Bot. 11/12, 114.

1955 Meded. Landb.hogesch. 55, 176.

1943 Pl. Phys, 18, 51.

1946 Proc. Am. Soc. Hort. Sci. 48, 417.

1961 Symposium on Ecology, London (in press). 